\title{
Poly(glycerol sebacate)-Based Polyester-Polyether Copolymers and Their Semi-Interpenetrated Networks with Thermoplastic Poly(ester-ether) Elastomers: Preparation and Properties
}

Runcy Wilson, ${ }^{\dagger}$ Anumon V. Divakaran, ${ }^{\dagger}$ Kiran S, ${ }^{\dagger}$ Anuraj Varyambath, ${ }^{\dagger}{ }^{\circ}$ Alaganandam Kumaran, ${ }^{\dagger}$ Swaminathan Sivaram, ${ }^{\ddagger}$ and Lakshminarayanan Ragupathy* ${ }^{* \dagger}$

${ }^{\dagger}$ Corporate R\&D Center, HLL Lifecare Limited, Akkulam PO, Sreekaryam, Trivandrum 695017, India

${ }^{\ddagger}$ Indian Institute of Science Education and Research, Dr. Homi Bhabha Road, Pune 411008, India

Supporting Information

ABSTRACT: Poly(glycerol sebacate) (PGS), produced from renewable monomers such as sebacic acid and glycerol, has been explored extensively for various biomedical applications. However, relatively less attention has been paid to explore PGS as sustainable materials in applications such as elastomers and rigid plastics, primarily because of serious deficiencies in physical properties of PGS. Here, we present two new approaches for enhancing the properties of PGS; (i) synthesizing block copolymers of PGS with poly(tetramethylene oxide)glycol (PTMO) and (ii) preparing a blend of PGS-b-PTMO with a poly(ester-ether) thermoplastic elastomer. The consequence of molar ratio (hard and soft segments) and $M_{\mathrm{n}}$ of soft segment on tensile properties of the material was investigated. The PGS- $b$-PTMO with 25:75 mole ratios of hard and soft segments and having a medium $M_{\mathrm{n}}$ soft segment $\left(5350 \mathrm{~g} \mathrm{~mol}^{-1}\right)$ exhibits an appreciable increase in percentage of elongation that is from $32 \%$ for PGS to $737 \%$. Blends of PGS- $b$-PTMO and a thermoplastic polyester elastomer, Hytrel 3078, form a semi-interpenetrated polymer network, which exhibits increased tensile strength to $2.11 \mathrm{MPa}$ and percentage of elongation to 2574 . An elongation of such magnitude is unprecedented in the literature for predominantly aliphatic polyesters and demonstrates that the simple polyester can be tailored for superior performance.

\section{INTRODUCTION}

An elastomer is a material that exhibits a rapid and reversible strain in response to a stress. ${ }^{1,2}$ Elastomeric materials can be classified as (a) thermoset elastomers (e.g., chemically crosslinked natural and synthetic elastomers) and (b) thermoplastic elastomers (TPEs; e.g., polyurethane, polyester-polyether copolymers, dynamically cross-linked PP-EPDM blends, etc.). ${ }^{3}$ TPEs are a class of polymers that behave similar to a thermoset rubber at below their melting or softening temperatures. Therefore, they are melt processable via thermoplastic processing methods. Unlike thermoset rubbers, TPEs can be easily reprocessed and remolded. The ability to process these materials with thermoplastic methods allows for the design and fabrication freedom that thermoset rubbers do not offer. ${ }^{4}$ TPEs derived from polyester-polyether (TPE-E) are an important subclass of TPEs that have been widely studied and are in commercial use. ${ }^{3}$ TPE-Es consist of a hard crystalline segment $[$ poly(butylene terephthalate) $(\mathrm{PBT})]$ and a soft amorphous segment [poly(tetramethylene oxide)glycol (PTMO)]. Crystalline PBT segment endows TPE-E with high $T_{\mathrm{m}}$, high strength, as well as chemical, wear, tear, heat and UV resistance. The amorphous polyether provides softness, elasticity, flexibility, resilience, and hydrolysis resistance. TPE-Es exhibit excellent abrasion resistance; high tensile, compressive, and tear strength; good flexibility over a wide range of temperatures; worthy hydrolytic stability; resistance to solvents; and fungus attack. Depending on hard and soft segment compositions, materials with a wide range of hardness can be produced. ${ }^{1,3,4}$

Recently, there has been many studies aimed at creating more sustainable elastomeric materials derived from aliphatic polyesters using renewable bio-derived monomers and capable of degradation under hydrolytic conditions. Several welldefined block copolymers derived from monomers such as $(+)$ lactide, $\varepsilon$-caprolactone, alkyl-substituted $\varepsilon$-caprolactone, and so forth have been reported with useful elastomeric properties. ${ }^{5-7}$ Poly(glycerol sebacate) (PGS) is a tough polyester elastomer with good flexibility (similar to vulcanized rubber) and has the attributes of biocompatibility and biodegradability. ${ }^{8-12}$ Most importantly, the monomer used for the preparation of PGS,

Received: September 20, 2018

Accepted: December 17, 2018

Published: December 28, 2018 
Scheme 1. Preparation of PGS-b-PTMO Using SA, PTMO, and Glycerol as Monomers

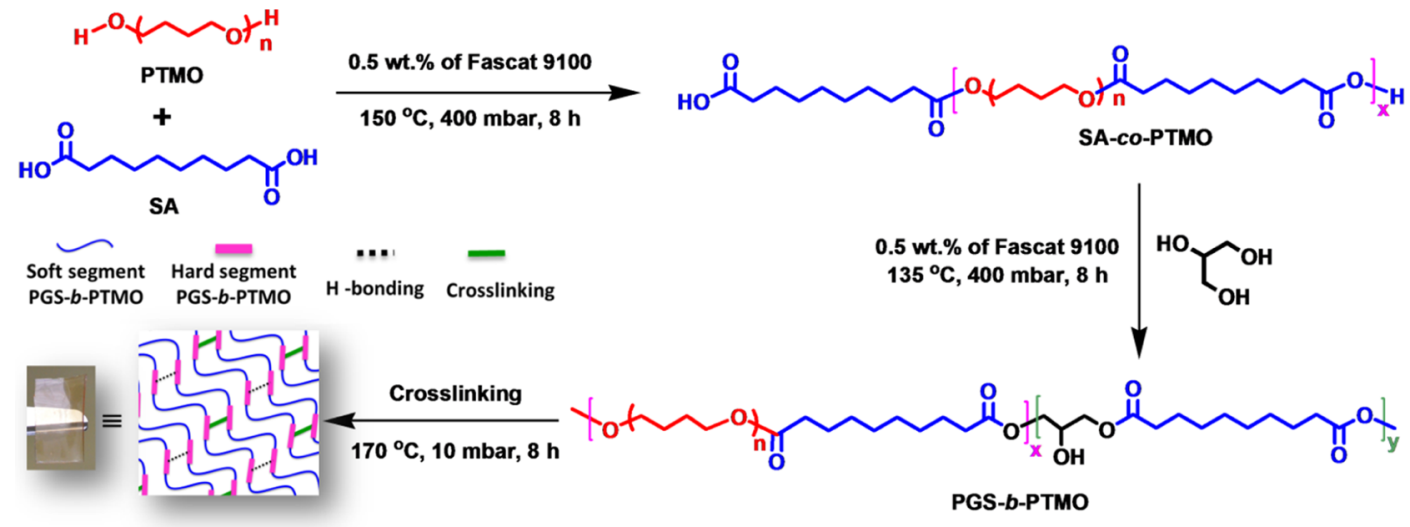

namely, glycerol and sebacic acid (SA), is bio-derived and renewable. They are available from natural fat splitting operations or byproduct of bio-diesel manufacturing (glycerol) and castor oil (SA). Thus, there is an increasing interest in developing useful products derived from PGS for a variety of sustainable elastomeric applications. PGS belongs to the family of aliphatic polyesters, which are currently attracting renewed attention because of the fact that they can be often derived from bio-renewable resources, and the resulting polymers can be degraded under composting conditions by a hydrolytic mechanism. Several recent reviews provide a comprehensive overview of the promise and challenge of creating a sustainable material platform based on aliphatic polyester to meet the diverse application needs of the society. $6,7,13-15$

PGS forms a covalently cross-linked, three-dimensional network of random coils with hydroxyl groups attached to the backbone. Cross-linking and hydrogen bonding interactions are responsible for the useful properties of this elastomer. PGS-based elastomers have been widely explored in biomedical applications, such as, hard to soft tissue engineering, controlled drug delivery, and tissue adhesives. ${ }^{16,17}$ Mechanical properties of PGS can be modulated using the following parameters: (a) curing temperature [Young's modulus $(E)$ of $0.056,0.22$, and $1.2 \mathrm{MPa}$ were observed at curing temperatures of 110,120 , and $130{ }^{\circ} \mathrm{C}$, respectively], ${ }^{18-20}$ (b) molar ratio of glycerol to SA [increasing glycerol molar ratio is seen to decrease the tangent modulus (slope of stress-strain curve) and vice versa,$^{20}$ (c) curing time (tangent modulus increases with the increasing curing time), ${ }^{20}$ (d) integrating acrylate monomers (e.g., $E$ of photocured PGS is $0.05-1.38 \mathrm{MPa}$ with respect to the degree of acrylation of $0.17-0.54),{ }^{21,22}$ (e) incorporating nanofillers ( $E$ is improved to $1.58 \mathrm{MPa}$ with the addition of $20 \%$ halloysite), ${ }^{23}$ (f) block polymers ( $E$ of PGS-co-poly(ethylene glycol) can be varied from $13 \mathrm{kPa}$ to $2.2 \mathrm{MPa}),{ }^{24}$ and $(\mathrm{g})$ blending with polymers (PGS)/poly(butylene succinate-linoleate) showed an increase of elastic modulus from 1.2 to $54 \mathrm{MPa}^{25}$

The focus of studies reported thus far has been predominantly on PGS materials suitable for biomedical applications and possesses a wide range of tensile strength $(0.3-100 \mathrm{MPa})$ and poor elongation properties $(10-120 \%)$. In most cases, the increased $E$ reduces the softness of materials (increases the rigidity) and makes it unsuitable for a number of skin-contacting elastomer applications (gloves, condoms, catheters, food wrappers, etc.). Thus, there is a need to explore new strategies for improving the properties of PGSbased polymers for their use in a wider range of applications.

In this article, we have explored two approaches to improve the mechanical properties of PGS. The first one is the preparation of block copolyester of PGS with a polyether, such as, PTMO constituting the soft block. The second approach is to blend PGS- $b$-PTMO with the readily available thermoplastic polyether-polyester elastomers consisting of a hard-crystalline segment composed of PBT and a soft-amorphous segment composed of PTMO. To the best of our knowledge, such an approach has not been examined so far in the earlier literature. ${ }^{26,27}$

\section{RESULTS AND DISCUSSION}

Preparation of Cross-linked Thin Films of PGS (1). PGS was prepared from a 1:1 molar mixture of SA and glycerol using 0.5 wt \% of FASCAT 9100 as a catalyst at $135^{\circ} \mathrm{C}$. The polymer was cross-linked using 4,4'-methylene bis(phenyl isocyanate) (MDI). The polymer before cross-linking had an $M_{\mathrm{n}}$ of $2320 \mathrm{~g} \mathrm{~mol}^{-1}$ and a polydispersity value of $\sim 10$. The structure of the cross-linked polymer was established using Fourier transform infrared (FT-IR) spectroscopy (Figure S1). FT-IR provides evidence for the ester bond formation, presence of the hydroxyl groups, and absence of the isocyanate band $\left(2270 \mathrm{~cm}^{-1}\right)$. In addition, the appearance of the $-\mathrm{NH}$ stretching at $3485 \mathrm{~cm}^{-1}$ in the cross-linked polymers provides evidence for the formation of urethane linkages.

Cross-linked PGS samples exhibit a broad sigmoidal melting peak $\left(T_{\mathrm{m}}\right)$ at -10 to $-15{ }^{\circ} \mathrm{C}$ and a glass transition at $-27{ }^{\circ} \mathrm{C}$ (Figures S2 and S3). These observations are in agreement with the data reported in the literature. ${ }^{19}$ The rubbery and amorphous nature of the cross-linked PGS is evident from its low $T_{\mathrm{g}}$ and weak $T_{\mathrm{m}}$. Cross-linked PGS is an elastic soft solid at room temperature. The stress-strain analysis of PGS cross-linked with 2 wt \% MDI exhibits a maximum tensile strength of $1.29 \pm 0.02 \mathrm{MPa}$ and an elongation at a break of $32 \%$ (Figure S4 and Table S1).

Synthesis of Cross-linked PGS-b-PTMO (3). With an objective to improve the mechanical properties of PGS, we prepared block copolyesters of PGS with PTMO. The relative mole ratio of soft and hard segments is likely to play an important role in determining the ultimate mechanical properties. ${ }^{28-30}$ Accordingly, three different block copolymer samples were prepared using a three-step process: in step 1, a polyester was prepared by reacting SA $(1 \mathrm{mmol})$ and PTMO $\left(M_{\mathrm{n}}: 250,0.65,0.75\right.$, and $\left.0.85 \mathrm{mmol}\right)$ using $0.5 \mathrm{wt} \%$ of 

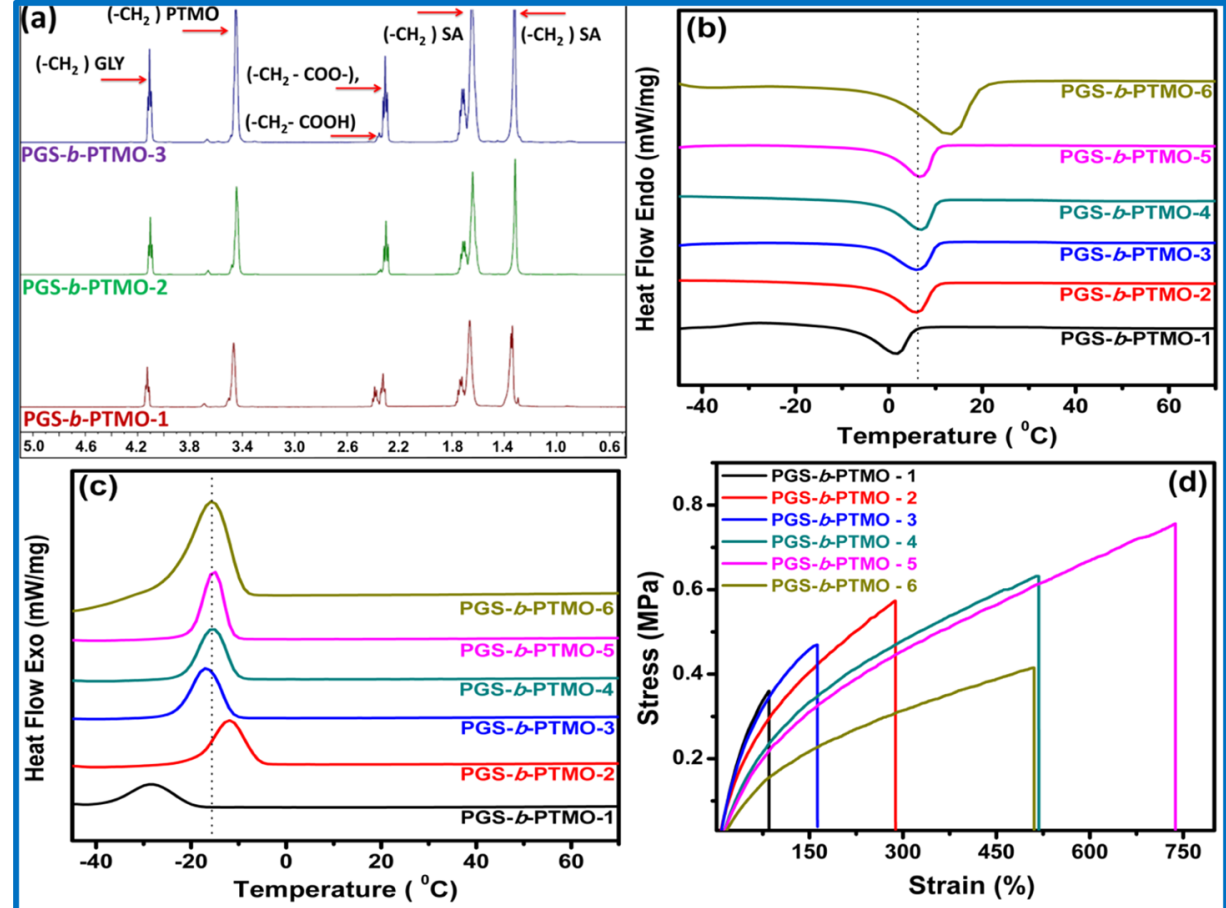

Figure 1. Microstructural, thermal, and mechanical characteristic of PGS-b-PTMO. (a) ${ }^{1} \mathrm{H}$ NMR spectrum; (b) DSC trace, heating curve; (c) DSC trace, cooling curve; and $(\mathrm{d})$ stress-strain behavior.

Table 1. Molecular, Thermal, and Mechanical Properties of PGS- $b$-PTMO Copolyesters

\begin{tabular}{|c|c|c|c|c|c|c|c|c|}
\hline samples & $\begin{array}{c}\text { stoichiometry } \\
\text { (SA/PTMO/glycerol) }\end{array}$ & $\begin{array}{c}M_{\mathrm{n}} \\
\left(\mathrm{g} \mathrm{mol}^{-1}\right)\end{array}$ & $M_{\mathrm{w}} / M_{\mathrm{n}}$ & $\begin{array}{l}\text { tensile strength } \\
\quad(\mathrm{MPa})\end{array}$ & $\begin{array}{c}\text { elongation at break } \\
(\%)\end{array}$ & 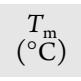 & $T_{\mathrm{c}}\left({ }^{\circ} \mathrm{C}\right)$ & $T_{\mathrm{g}}\left({ }^{\circ} \mathrm{C}\right)$ \\
\hline $\begin{array}{l}\text { PGS (cross-linked with } 2 \text { wt } \% \\
\text { MDI) }\end{array}$ & $1.00: 0.00: 1.00$ & 2320 & 10 & $1.29 \pm 0.02$ & 32 & -10.0 & -21.8 & -26.0 \\
\hline PTMO & 0.00:1.00:0.00 & $250^{a}$ & & & & -39.2 & -10.6 & -54.0 \\
\hline SA-co-PTMO & $1.00: 0.95: 0.00$ & & & & & -1.0 & 21 & \\
\hline (PGS-b-PTMO)-1 & $1.00: 0.65: 0.35$ & 1070 & 2.3 & $0.36 \pm 0.02$ & $085 \pm 30$ & 2.2 & -28.3 & -57.0 \\
\hline (PGS-b-PTMO)-2 & $1.00: 0.75: 0.25$ & 2040 & 2.6 & $0.57 \pm 0.06$ & $287 \pm 30$ & 5.1 & -24.0 & -60.0 \\
\hline (PGS-b-PTMO)-3 & $1.00: 0.85: 0.15$ & 2820 & 2.2 & $0.46 \pm 0.09$ & $162 \pm 60$ & 9.2 & -20.0 & -67.0 \\
\hline (PGS-b-PTMO)-4 & $1.14: 0.85: 0.29$ & $2640^{b}$ & 1.5 & $0.63 \pm 0.05$ & $517 \pm 18$ & 6.6 & -15.7 & -60.0 \\
\hline (PGS- $b$-PTMO)-5 & $1.25: 0.95: 0.30$ & $5350^{b}$ & 2.5 & $0.75 \pm 0.01$ & $737 \pm 30$ & 6.8 & -15.3 & -63.0 \\
\hline (PGS-b-PTMO)-6 & $1.33: 1.00: 0.33$ & $7960^{b}$ & 4.6 & $0.41 \pm 0.05$ & $510 \pm 30$ & 13.2 & -15.9 & -58.0 \\
\hline
\end{tabular}

${ }^{a}$ Specified by Sigma-Aldrich. ${ }^{b}$ Represents the $M_{\mathrm{n}}$ of the soft segments produced from SA and PTMO.

FASCAT 9100 as a catalyst at $150{ }^{\circ} \mathrm{C}$ at a pressure of 400 mbar [poly(tetramethylene glycol sebacate) (SA-co-PTMO) is shown in Scheme 1]. In step 2, glycerol (0.35, 0.25, and 0.15 $\mathrm{mmol}$ ) was reacted with the polymer obtained in step 1 at 135 ${ }^{\circ} \mathrm{C}$ for $8 \mathrm{~h}$ in vacuo (PGS- $b$-PTMO, 1 to 3 ). In step 3 , the product obtained from step 2 was cross-linked with MDI. The reactions are illustrated in Scheme 1. Here, the soft segments of PTMO are colored red, and the PGS hard segment is colored blue.

The ${ }^{1} \mathrm{H}$ NMR of the polymer obtained after step 2 is shown in Figure 1a. The three peaks at $\delta 1.30$ and $1.61 \mathrm{ppm}$ are assigned to the methylene protons of SA, and the peak at $\delta$ $4.12 \mathrm{ppm}$ is due to the methylene protons on glycerol. The peak at $\delta 3.45 \mathrm{ppm}$ corresponds to the methylene protons of PTMO. The signals at $\delta 2.3$ and $2.4 \mathrm{ppm}$ are assigned to ester $\left(-\mathrm{CH}_{2} \mathrm{COO}-\right)$ and acid $\left(-\mathrm{CH}_{2}-\mathrm{COOH}\right)$ groups, indicating the conversion of acid into ester. GPC data of the polymers obtained after step 2 are shown in Table 1 .

Differential scanning calorimetry (DSC) of PGS- $b$-PTMO-1 to 3 is shown in Figure $1 \mathrm{~b}, \mathrm{c}$. The $T_{\mathrm{g}}$ and $T_{\mathrm{m}}$ of PTMO are -54 and $\sim-39^{\circ} \mathrm{C}$, respectively, whereas the $T_{\mathrm{g}}$ and $T_{\mathrm{m}}$ of PGS are -30 and $-10{ }^{\circ} \mathrm{C}$, respectively. ${ }^{31}$ The polyester produced from SA and PTMO (SA-co-PTMO) shows a $T_{\mathrm{m}}$ at $-1.0^{\circ} \mathrm{C}$ and no discernible $T_{\mathrm{g}}$ (Figure S5). This indicates that this polyester is weakly crystalline. However, the obtained block copolyester samples (PGS- $b$-PTMO-1 to 3 ) exhibit relatively a low $T_{\mathrm{g}}$ at $-60{ }^{\circ} \mathrm{C}$ (Figures S8 and S9) and a $T_{\mathrm{m}}$ in the range of $2-9^{\circ} \mathrm{C}$ (Figure $1 \mathrm{~b}, \mathrm{c}$ ). This indicates that both of the segments (i.e., PGS and SA-co-PTMO) are completely miscible, and the flexibility of copolyesters is increased significantly. Miscibility of both of the segments may be because of the chemical similarity of succinic acid segment monomers in both of the blocks, whereas the improvement in chain flexibility of block copolymers could be ascribed to the presence of a flexible PTMO segment.

PGS- $b$-PTMO-1 to 3 exhibit nonlinear stress-strain behavior (Figure 1d) typical of elastomers. Polymer films produced from 1:0.75:0.25 monomer ratios [SA, PTMO, and PGS (PGS-b-PTMO-2)] display higher tensile strength (0.57 $\mathrm{MPa}$ ) and percentage of elongation (287). The block 

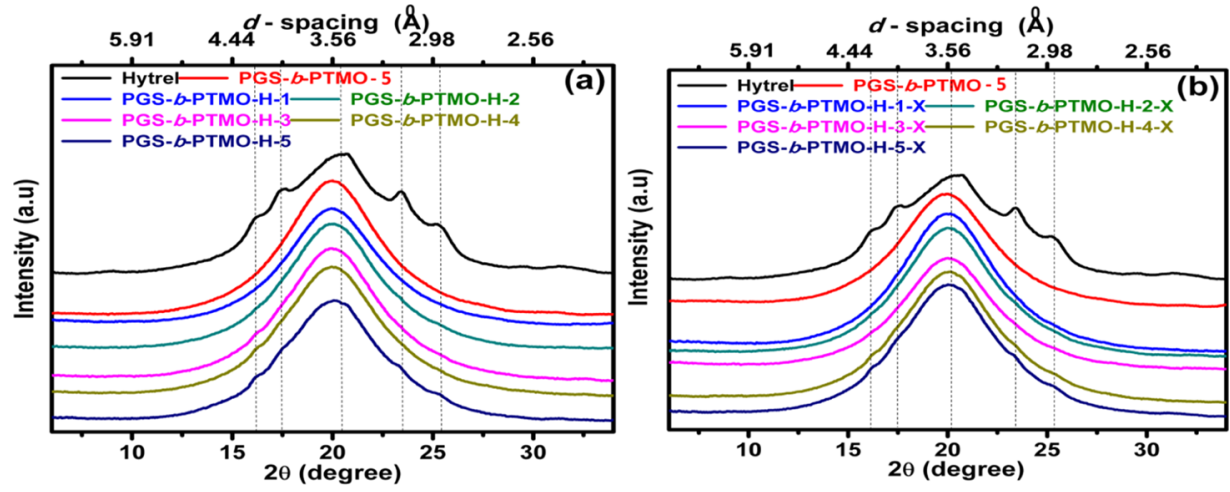

Figure 2. Wide-angle XRD patterns of PGS-b-PTMO-5, Hytrel 3078, and the blends (a) without cross-linker and (b) and with cross-linker.

copolyesters show a ninefold increment in the percentage of elongation compared to cross-linked PGS alone (Table 1). However, this is accompanied by a reduction in tensile strength. As noted above, the block copolyester, PGS- $b$ PTMO-2, with a 75:25 mole ratio of PTMO and PGS exhibits better elastic properties. With a view to investigate the effect of $M_{\mathrm{n}}$ of soft segment on stress-strain properties, copolyester samples with soft segment $M_{\mathrm{n}}$ of $\left(M_{\mathrm{n}} 2640,5350\right.$, and $7960 \mathrm{~g}$ $\left.\mathrm{mol}^{-1}\right)$ were prepared by the reaction of SA $(1 \mathrm{mmol})$ and PTMO $(0.85,0.95$, and $1 \mathrm{mmol})$ at $400 \mathrm{mbar}$ pressure and $150{ }^{\circ} \mathrm{C}$ for $12 \mathrm{~h}$ (step 1$)$. In step 2, SA $(0.14,0.25$, and 0.33 $\mathrm{mmol})$ and glycerol $(0.29,0.30$, and $0.33 \mathrm{mmol})$ were added to realize an overall mole ratio of soft and hard segments of 75:25, and the reaction was performed at $135{ }^{\circ} \mathrm{C}$ for $8 \mathrm{~h}$ under 400 mbar pressure. In step 3 , the sample obtained from step 2 was dissolved in chloroform, reacted with MDI (2 wt \% of hard segments), and the films were cast from the solution. Subsequently, the cast film was cross-linked at $170{ }^{\circ} \mathrm{C}$ for 6-7 h under 5 mbar pressures to obtain thin elastic films.

The DSC data of the PGS- $b$-PTMO-4 to 6 are shown in Figures $1 \mathrm{~b}, \mathrm{c}, \mathrm{S} 8$, and $\mathrm{S} 9$ and Table 1 . These block copolyesters (PGS-b-PTMO-4 to 6) also exhibit a discernible $T_{\mathrm{g}}$ at $-60{ }^{\circ} \mathrm{C}$ (Figures $\mathrm{S} 8$ and S9) and a $T_{\mathrm{m}}$ in the range of $6-13^{\circ} \mathrm{C}$ (Figure $1 \mathrm{~b}, \mathrm{c})$. This indicates that these materials are rubbery in nature. Among the block copolymers studied, PGS- $b$-PTMO-6 sample shows a higher and broad $T_{\mathrm{m}}$ at $13.2^{\circ} \mathrm{C}$. This suggests that the higher $M_{\mathrm{n}}\left(7960 \mathrm{~g} \mathrm{~mol}^{-1}\right)$ of the soft segment (SA-co-PTMO) may have limited miscibility in the PGS phase.

PGS- $b$-PTMO-5 produced from the 1.25:0.95:0.30 monomer ratio of SA, PTMO, and glycerol and cross-linked with MDI shows better tensile strength $(0.76 \mathrm{MPa})$ and percentage of elongation (737) (Table 1 and Figure 1d). Increasing the $M_{\mathrm{n}}$ of soft segment to $5350 \mathrm{~g} \mathrm{~mol}^{-1}$ resulted in an increase of percentage of elongation to 737. For reasons not wellunderstood, further increase in $M_{\mathrm{n}}$ of the soft segment resulted in loss of elongation. Thus, the elastic property of PGS could be improved by substantially using a simple approach of forming a block copolymer of PGS with PTMO. PTMO is produced from the ring-opening polymerization of tetrahydrofuran (THF), which could also be considered as a bioderived monomer because THF can be produced from bioderived succinic acid. Thus, the copolymer PGS- $b$-PTMO can be considered as an elastomer that is entirely derived bioresources and hydrolytically degradable, two key attributes of sustainability.

Semi-Interpenetrating Polymer Networks Derived from Copolyesters PGS-b-PTMO-5 and Hytrel 3078.
Interpenetrating polymer networks (IPNs) refer to a blend of cross-linked polymers in which two chemically distinct macromolecular networks coexist, ideally having a structure, that is, homogeneous down to the molecular level. ${ }^{26,32,33}$ IPNs are classified as semi and full IPNs, depending on whether one or both of the two components are cross-linked. IPNs are prepared by three general routes: (i) by mixing two monomers, which are subsequently (and often simultaneously) polymerized and cross-linked, (ii) by dissolving a monomer in an another polymer network followed by its polymerization to form the second interpenetrating network, and (iii) by blending two polymers that are thermodynamically miscible, followed by cross-linking. ${ }^{34,35}$

We have prepared a semi-IPN (S-IPN) of PGS- $b$-PTMO with commercially available thermoplastic polyester, Hytrel 3078, and characterized by X-ray diffraction (XRD), DSC and universal testing machine. Several grades of thermoplastic polyester polyether elastomers (TPE-Es) are commercially available and exhibit a wide balance of flexibility/stiffness properties. ${ }^{36,37}$ Therefore, there is a huge potential to prepare elastomers with a wide range of physical and mechanical properties.

We anticipated good compatibility between two chosen polymers on account of the presence of segments of PTMO blocks in both of the constituent polymers. Accordingly, blends of PGS- $b$-PTMO-5 (prepared from 1.14:0.95:0.29 ratio of SA, PTMO, and glycerol) and Hytrel 3078 (10, 20, 30, 40, and 50 wt \%) with and without MDI ( 2 wt \% of MDI with respect to glycerol) were prepared by solution blending. The resulting thin films were transparent and elastic (Figure 6). When one of the constituent polymers, namely PGS- $b$-PTMO-5, is crosslinked using MDI, a semi-interpenetrating structure will be resulted, in which the Hytrel 3078 will interpenetrate into the cross-linked chain segments of PGS-b-PTMO-5.

Microstructural Characterization of S-IPNs. The XRD of the blend, with and without MDI, is shown in Figure 2a,b. The XRD patterns of neat Hytrel 3078 showed five characteristic peaks centered at a $d$-spacing of $5.45 \AA(2 \theta=$ 16.23), $5.06 \AA(2 \theta=17.48), 4.29 \AA(2 \theta=20.66), 3.78 \AA(2 \theta=$ $23.48)$, and $3.51 \AA(2 \theta=25.34)$, which can be attributed to the $011,010,101,100$, and 111 reflections of Hytrel unit cell, respectively. ${ }^{38}$ The observed diffraction patterns represent PBT (attributed to the crystalline structure of the hard polyester block of Hytrel 3078), whereas the strong scattering background is due to the amorphous polyether (PTMO) block of Hytrel 3078. On the contrary, PGS-b-PTMO-5 exhibits a 

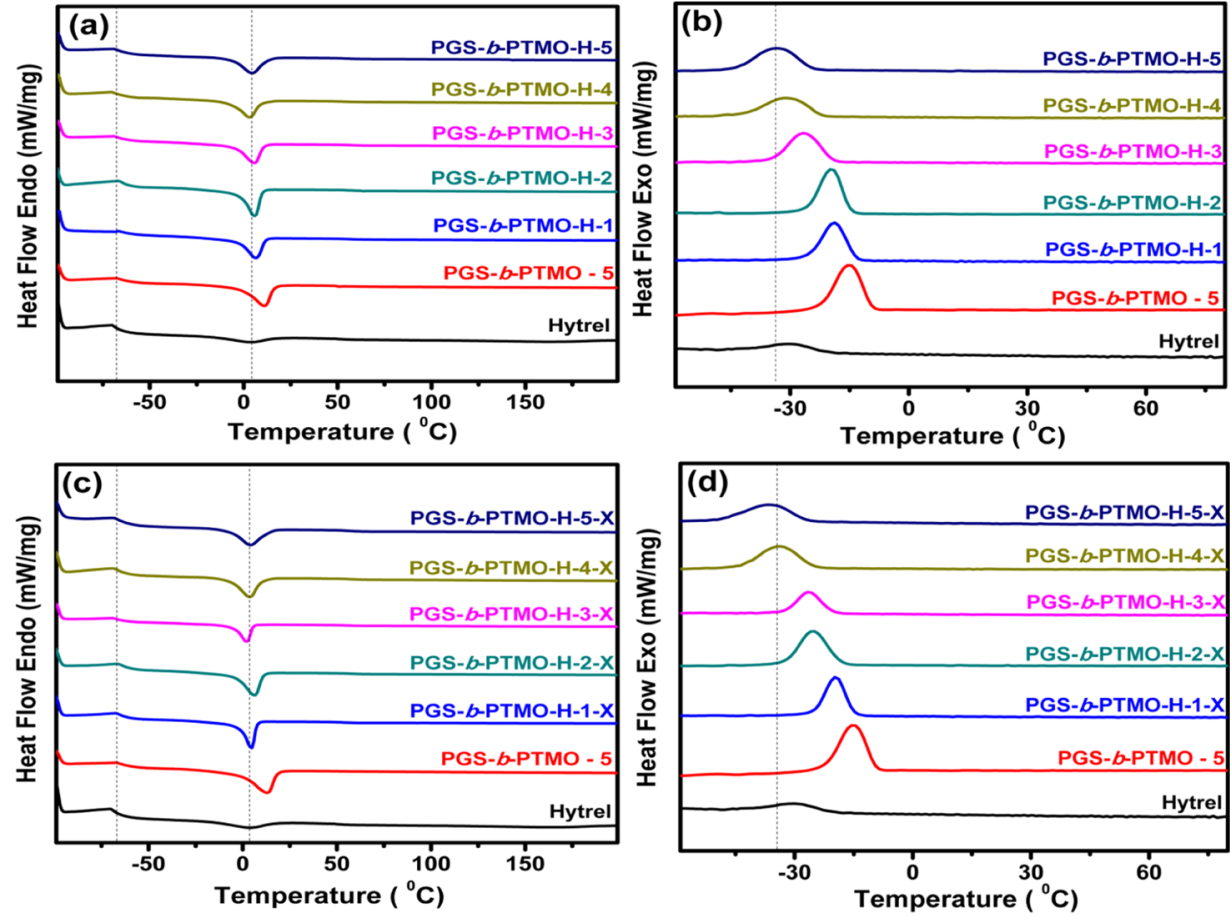

Figure 3. DSC thermogram of heating and cooling cycles of the blends (a,b) without a cross-linker (i.e., MDI) and (c,d) with a cross-linker (i.e., MDI).
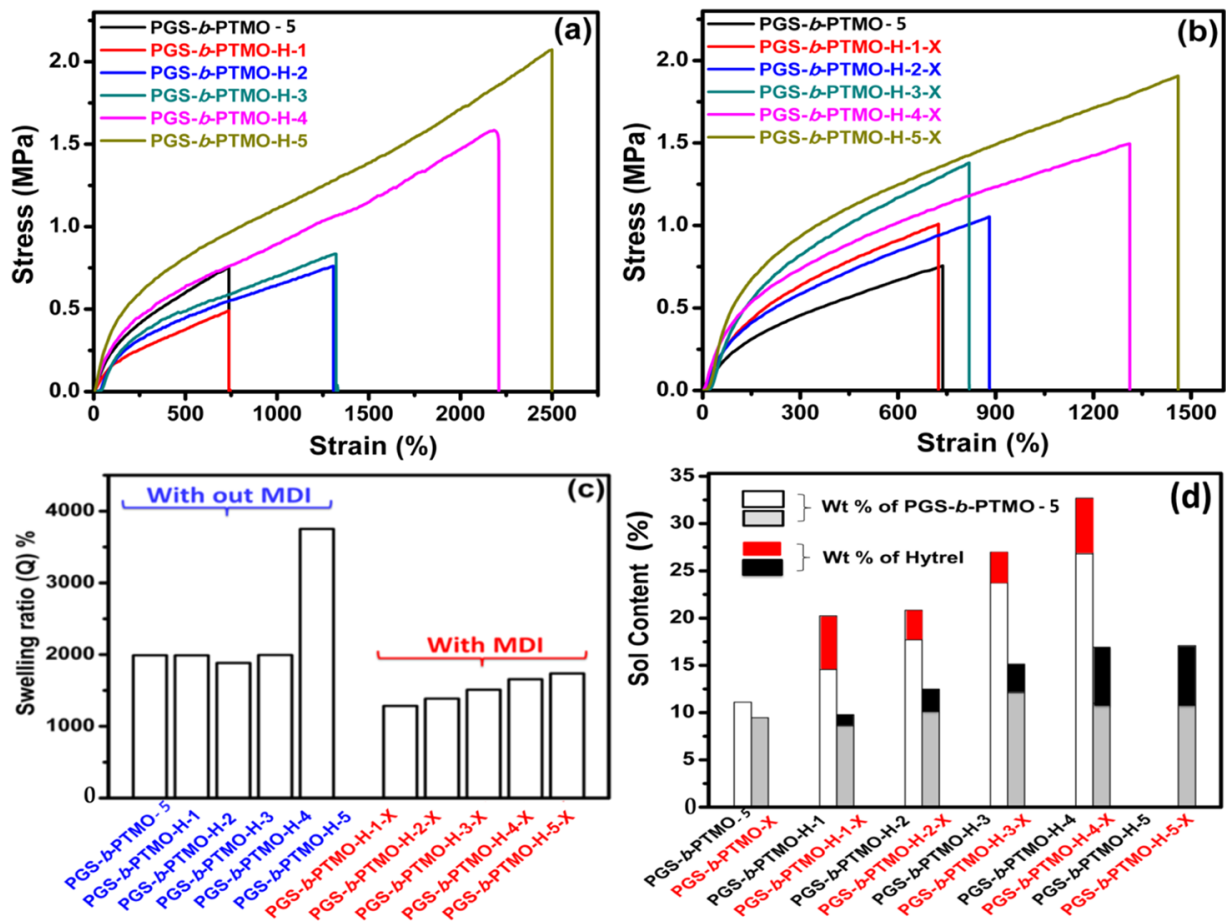

Figure 4. Tensile properties of the blend samples prepared (a) without a cross-linker (i.e., MDI) and (b) with a cross-linker (i.e., MDI). Blend samples' (c) swelling ratio (without and with MDI) and (d) sol content (without and with MDI) in which wt \% of leached PGS-b-PTMO-5 and Hytrel from the S-IPN in $\mathrm{CHCl}_{3}$ are also incorporated.

broad halo peak centered at a $d$-spacing of $4.42 \AA(20.04)$, which is characteristic of an amorphous polymer.

When the content of Hytrel 3078 was low, that is, 10 and 20 wt \%, the blends show only a broad amorphous peak similar to PGS- $b$-PTMO-5. However, with higher amounts of Hytrel 3078 (30 and $40 \mathrm{wt} \%$ ), the blends show that Hytrel's five characteristic peaks are superimposed with PGS-b-PTMO-5's broad peak. At 50 wt \% of Hytrel, the blend displays small humps of Hytrel's representative peaks. All of these results indicate that the crystalline regions of the Hytrel (because of PBT) may be affected by the presence of PGS- $b$-PTMO-5 and could form an S-IPN. XRD patterns are observed to be similar for both the non-cross-linked and cross-linked blends. 
Scheme 2. Representation of the Formation of S-IPN between PGS-b-PTMO and Hytrel

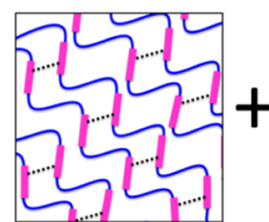

PGS- $b$-PTMO

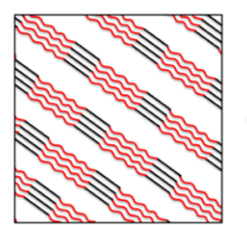

Hytrel

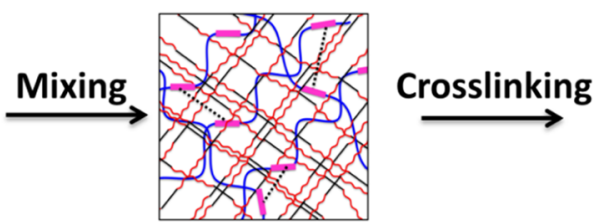

PGS-b-PTMO/Hytrel Blends
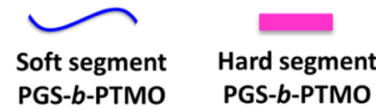

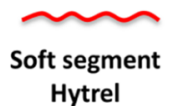

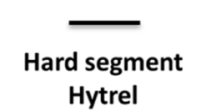

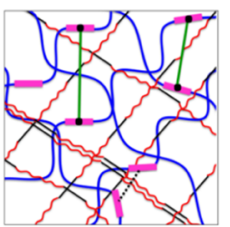

Semi - IPN Network

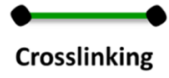

$T_{\mathrm{m}}$ and $T_{\mathrm{g}}$ of the blend samples are shown in Figure 3 and Table S2. All samples show a single $T_{\mathrm{g}}$ (between 63.6 and $-72.3{ }^{\circ} \mathrm{C}$ ) indicating the rubbery nature of the produced materials. Hytrel 3078 shows $T_{\mathrm{g}}$ at $-65.3{ }^{\circ} \mathrm{C}$ with two broad $T_{\mathrm{m}} \mathrm{s}$ at 4.1 and $164{ }^{\circ} \mathrm{C}\left(T_{\mathrm{c}}=-30\right.$ and $100{ }^{\circ} \mathrm{C}$, respectively $)$ (Figure S10). The broad melting peaks are due to the polydispersed lamellar thickness (crystalline) of the hard segments (PBT). The supplier's (DuPont) data sheet provides the value of $T_{\mathrm{g}}$ of $-60{ }^{\circ} \mathrm{C}$ and $T_{\mathrm{m}}$ of $177^{\circ} \mathrm{C}$. PGS- $b$-PTMO-5 displays a sharp $T_{\mathrm{m}}$ at $11.1{ }^{\circ} \mathrm{C}\left(T_{\mathrm{c}}=-17.6{ }^{\circ} \mathrm{C}\right)$. Nearly, monodispersed crystalline regions of PGS may be the reason for a sharp melting peak.

When Hytrel 3078 is blended with PGS- $b$-PTMO-5, two broad melting peaks at 4.1 and $164{ }^{\circ} \mathrm{C}$ corresponding to Hytrel 3078 disappeared and a new sharp $T_{\mathrm{m}}$ is observed between 3.1 and $6.6{ }^{\circ} \mathrm{C}$. This is because of the formation of S-IPN, which does not allow the Hytrel's hard segment to crystallize; therefore, the two $T_{\mathrm{m}} \mathrm{s}$ vanished and supported the XRD findings. Increasing the percentage of Hytrel (10-40 wt \%) caused $T_{\mathrm{m}}$ to decrease from 6.6 to $3.1{ }^{\circ} \mathrm{C}$. Upon further increase in the Hytrel 3078 content to $50 \mathrm{wt} \%, T_{\mathrm{m}}$ showed a small increase to $4.4{ }^{\circ} \mathrm{C} . T_{\mathrm{c}}$ is decreased from -18.9 to -33.6 ${ }^{\circ} \mathrm{C}$ (near the Hytrel's broad $T_{\mathrm{c}}$ at $-30{ }^{\circ} \mathrm{C}$ ) with an increasing Hytrel 3078 from 10 to $50 \mathrm{wt} \%$. In addition, broadening of the crystallization peak was observed. This indicates that the increased amount of Hytrel in the blend system affects the crystallization behavior of PGS- $b$-PTMO-5; therefore, a clear downward shifting and broadening of $T_{\mathrm{c}}$ are observed. The blend samples with MDI also showed a similar melting and crystallization behavior $\left(T_{\mathrm{m}}\right.$ and $T_{\mathrm{c}}$ between $2.2-4.7$ and -19.7 to $-36.8{ }^{\circ} \mathrm{C}$, respectively).

These observations suggest that the blends of Hytrel 3078 with PGS- $b$-PTMO-5 are miscible at a molecular level. The ability of the hard segment in Hytrel 3078 to crystallize is inhibited by the presence of PGS- $b$-PTMO segments. Interestingly, the presence of Hytrel 3078 in the blend does not inhibit the weak crystallization tendency of PGS- $b$-PTMO. However, the increasing amount of Hytrel wt \% inhibits the crystallization of PGS- $b$-PTMO. Therefore, the shifting of $T_{\mathrm{m}}$ is observed toward Hytrel's $T_{\mathrm{m}}$ when the amount of Hytrel is increased in the blend system.

The thin film of the blend, with and without MDI, was subjected to stress-strain analysis, and the results are shown as Figure 4a,b and Table S2. For comparison, the stress-strain properties of Hytrel 3078 were also measured using thin-film specimens of the same dimensions and processing conditions as used for the blends (i.e., PGS-b-PTMO-H-1 to 6). The obtained tensile strength $(0.44 \mathrm{MPa})$ and percentage of elongation (342) for Hytrel 3078 were lower than what are reported using specimens of ASTM dimensions. The difference in properties could be because of differing dimensions of the specimens and the processing conditions.

The blend samples, PGS- $b$-PTMO-Hytrel-1, show a lower tensile strength compared to PGS- $b$-PTMO. This may be because of the fact that both of the materials are miscible and addition of $10 \mathrm{wt} \%$ of Hytrel disrupts the physical (Hbonding) and chemical linkages between the chains of PGS- $b$ PTMO. However, PGS-b-PTMO-Hytrel 3078 (2-5) shows an increase of tensile strength with increasing Hytrel 3078 content in the blend compared to the parent materials. On the contrary, elongation increased significantly by the addition of Hytrel 3078, from 737 to $2574 \%$. The inability of the hard segment in Hytrel 3078 to crystallize by the addition of PGS- $b$ PTMO could be the reason why there is little improvement in tensile strength in the blend system (Scheme 2).

In this instance, PGS- $b$-PTMO acts similar to a "plasticizer" to Hytrel 3078, causing a reduction in resistance to strain because of the plasticization of the crystalline domain. This, in turn, leads to a significant increase in elongation far in excess of that observed individually for either Hytrel 3078 (342\%) or PGS-b-PTMO-5 (737\%). As anticipated, cross-linking the PGS- $b$-PTMO-5 segment caused a reduction in the percentage of elongation; however, the values were still higher than that of the individual constituents. At the same time, the tensile strength of cross-linked materials showed a marginal decrease in the case of 60:40 and 50:50 blends, that is, PGS- $b$-PTMOH-4-X and PGS-b-PTMO-H-5-X (1.49 and $1.90 \mathrm{MPa})$ when compared to the similar composition of non-cross-linked blends (PGS- $b$-PTMO-H-4 and PGS- $b$-PTMO-H-5) (1.58 and $2.11 \mathrm{MPa})$. This can be ascribed to the cross-linking of PGS- $b$ PTMO with MDI, which reduces the elastic nature of the material and could inhibit the strain-induced crystallization of the hard segments of Hytrel. In contrast, non-cross-linked blends (i.e., without MDI) form a more flexible network, which could allow the strain-induced crystallization of the hard segments of Hytrel.

Swelling Behavior and Sol Content of the Blends. The swelling ratio and the sol content of the blend samples (PGS- $b$ PTMO-Hytrel 3078) were determined (Figure 4c,d). The swelling ratio is observed to be constant up to $30 \mathrm{wt} \%$ of Hytrel 3078 content in the blend. Further increase in the Hytrel 3078 content to $40 \%$ almost doubles the swelling ratio. The blend prepared with 50 wt \% Hytrel 3078 was brittle and could not be recovered as a whole. The high solubility of Hytrel 3078 in chloroform could be the reason for this observation. The cross-linked blends with MDI show significantly lower propensity for swelling compared to noncross-linked samples; however, a steady increase is observed 
Table 2. Comparison of Thermal and Tensile Properties of PGS-b-PTMO-5, Hytrel, and Its Blends with Some Typical Aliphatic Polyester Elastomers and Natural Rubber

\begin{tabular}{|c|c|c|c|c|c|c|c|}
\hline $\begin{array}{l}\text { s. } \\
\text { no. }\end{array}$ & polymer & $T_{\mathrm{g}}\left({ }^{\circ} \mathrm{C}\right)$ & $T_{\mathrm{m}}\left({ }^{\circ} \mathrm{C}\right)$ & $\begin{array}{l}\text { tensile strength } \\
\qquad(\mathrm{MPa})^{a}\end{array}$ & $\begin{array}{l}\text { modulus } \\
(\mathrm{MPa})^{a}\end{array}$ & $\begin{array}{c}\% \text { of } \\
\text { elongation }^{a}\end{array}$ & refs \\
\hline 1 & poly(butylene succinate) & -32 & 114 & 34 & 589 & 560 & 39 \\
\hline 2 & poly(butylene succinate adipate) & -45 & 96 & 19 & 250 & 807 & 39 \\
\hline 3 & $\begin{array}{l}\text { poly(L-lactide- } \varepsilon \text {-caprolactone- } \varepsilon \text {-decalactone) block } \\
\text { polymer }\end{array}$ & -60 & & 9.9 & 1.5 & 2100 & 40 \\
\hline 4 & Hytrel 3078 & -65 & 4.1 and 164 & 0.44 & 0.014 & 342 & this work \\
\hline 5 & PGS-b-PTMO-5 (without cross-linker) & -57 & 7.8 & 0.37 & 0.009 & 353 & this work \\
\hline 6 & PGS-b-PTMO-5 (with cross-linker) & -63 & 6.8 & 0.75 & 0.013 & 737 & this work \\
\hline 7 & PGS-b-PTMO-Hytrel 3078 (without cross-linker) & -66 & 4.4 & 2.1 & 0.018 & 2574 & this work \\
\hline 8 & PGS-b-PTMO-Hytrel 3078 (with cross-linker) & -65 & 4.4 & 1.9 & 0.005 & 1460 & this work \\
\hline 9 & cross-linked natural rubber & -73 & & 25.0 & 1.6 & 869 & 41 \\
\hline
\end{tabular}

${ }^{a}$ For s. no. 3 and 9, dog-bone-shaped and ring samples (ASTM-3492 standards) were employed, respectively, for measuring the tensile properties, whereas for s. no. 1 and 2, the sample dimension details are not reported.

with the content of Hytrel 3078 in the blend. This is due to the increased cross-linking density.

PGS- $b$-PTMO and cross-linked PGS- $b$-PTMO samples show a lower sol content, that is, 12 and $8 \mathrm{wt} \%$, respectively, compared to the corresponding blends with Hytrel 3078. The sol content (wt \%) is observed to be increased with the increasing wt \% of Hytrel 3078. When the wt \% of Hytrel 3078 is 10 , PGS- $b$-PTMO-H-1 (without MDI) shows 20 wt \% sol content, whereas PGS- $b$-PTMO-H-1-X (with MDI) has a sol content similar to PGS- $b$-PTMO-X. Increasing the amount of Hytrel 3078 to 20 wt \% (PGS- $b$-PTMO-H-2) did not cause the sol content to increase; however, 30 and 40 wt $\%$ of Hytrel 3078-containing materials (PGS- $b$-PTMO-H-3 and PGS- $b$ PTMO-H-4) show a higher sol content that is 28 and 35 wt \%, respectively. The sample containing 50 wt \% of Hytrel 3078 (PGS-b-PTMO-H-5) became brittle upon immersion in chloroform and not possible to calculate the sol content. With cross-linked materials (PGS- $b$-PTMO-H-2-X to $4-\mathrm{X}$ ), the sol content was found to increase with an increasing content of Hytrel 3078 up to 40 wt \%. In summary, cross-linked blends show lower sol content compared to non-cross-linked blends. When MDI is used as a cross-linker, covalent urethane linkages are formed increasing the network density. In the absence of the added cross-linker, the blends possess only physical crosslinks (H-bonding) resulting in a reduced network density. Thus, the swelling ratio and the sol content are observed to be higher.

The ${ }^{1} \mathrm{H}$ NMR spectrum of Hytrel 3078 is shown in Figure S11. By comparing the intensity of aromatic ${ }^{1} \mathrm{H}(8.1 \mathrm{ppm})$ and $\mathrm{CH}_{2}$ protons sitting next to $-\mathrm{O}-$ group in PTMO (3.4 ppm), the $M_{\mathrm{n}}$ of PTMO was calculated as $1100 \mathrm{~g} \mathrm{~mol}^{-1}$. From the ratio of signals corresponding to $\mathrm{CH}_{2}$ protons sitting next to -COO- [4.4 and 4.3 ppm corresponds to PTMO and butane diol (BD), respectively], the ratio of PTMO and BD phase was calculated to be 72 and $28 \mathrm{~mol} \%$, respectively. Correspondingly, the wt \% of terephthalic acid (TA) group in Hytrel is calculated as 30.4.

The ${ }^{1} \mathrm{H}$ NMR analysis of the sol content of the blend samples is given in Figure S12. In Hytrel, wt \% of TA is 30.4, whereas in PGS-PTMO, wt \% of SA is 49.6. As we know, the aromatic protons (from Hytrel) are observed at $8.1 \mathrm{ppm}$, whereas $-\mathrm{CH}_{2}-\mathrm{COO}-$ (represents PGS- $b$-PTMO-5) is seen at $2.2 \mathrm{ppm}$. In an ideal 50:50 wt \% mixture of both might show the intensity 0.34 (TA) and 0.496 (SA). By integrating both of the peaks and dividing by 0.34 and 0.496 , respectively, the wt
$\%$ of Hytrel and PGS-PTMO-5 was calculated and incorporated in Figure 4d.

${ }^{1} \mathrm{H}$ NMR spectra of the sol contents indicate that only oligomers (of PGS-b-PTMO-5) and Hytrel 3078 leach out from the thin film material (while at $\mathrm{CHCl}_{3}$ ) in both cases, that is, with and without MDI. In this case, blend samples prepared without MDI show that by increasing the wt \% of Hytrel from 10 to 20 and $30 \%$ has decreased the Hytrel 3078 leaching from 28 to $15 \mathrm{wt} \%$. Further increasing the Hytrel 3078 wt \% to 40 in the blend has made a small increment in the wt \% of Hytrel 3078 leaching to 18 . This material shows the highest percentage of elongation, that is, $2574 .{ }^{1} \mathrm{H}$ NMR of sol content of the samples prepared with MDI is also given in Figure S12. Here, in contrast, increasing the wt \% of Hytrel 3078 (in the blend) from 10 to 20 and 30 has increased the wt $\%$ of Hytrel leaching from 12 to 20 . Further increasing the wt $\%$ of Hytrel to 40 and 50 has significantly increased the leaching Hytrel 3078 wt \% to 35 . This suggests that crosslinking with MDI possibly increases the phase separation between Hytrel 3078 and PGS-b-PTMO. However, in the blend prepared without MDI, the miscibility between Hytrel 3078 and PGS- $b$-PTMO is enhanced leading to the observed higher percentage of elongation.

\section{CONCLUSIONS}

PGS is a class of cross-linkable aliphatic polyesters derived from biorenewable monomers, namely, glycerol and SA. Crosslinked PGS show poor tensile strength and elongation properties. We demonstrate herein that incorporating a soft segment in PGS, namely PTMO (75 mol \%), results in an amorphous block copolymer, which exhibits a significant increase in elongation, from $32 \%$ for PGS to $730 \%$ for PGS- $b$ PTMO. The fact that PTMO can also be derived from biorenewable resources makes such a polyester- $b$-polyether a sustainable elastic material. We have further demonstrated that the blending of PGS- $b$-PTMO with a thermoplastic poly(ester-ether) elastomer (Hytrel 3078) can lead to a semiinterpenetrating network polymer, exhibiting further improvements in both tensile strength and elongation. Using appropriate composition of materials, an elongation of up to $2500 \%$ was obtained. To the best of our knowledge, such high elongation properties have never been observed for predominantly aliphatic polyesters. A summary of properties of materials reported in this article with a few similar materials available in the literature are given in Table 2 and Figure 5, 
which support our contention. Furthermore, the produced films are transparent and tough.

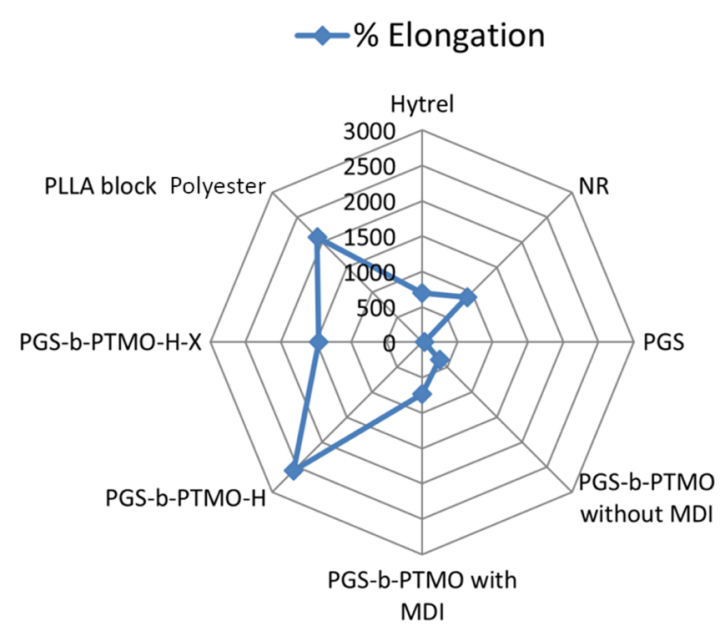

Figure 5. Evaluation of the percentage of elongation of PGS-based elastomers (documented in this article) with some of the typical polyester elastomers and natural rubber.

Using a wide variety of physicochemical methods, we have examined the structure of such materials. It is demonstrated that the block copolymer of PGS and PTMO is a single-phase weakly crystalline polymer having a single $T_{\mathrm{g}}$. We further propose that the PGS- $b$-PTMO copolyester acts as an efficient plasticizer by inhibiting the crystallization of the hard blocks of Hytrel 3078, resulting in a synergistic improvement in elongation to an unprecedented level. The cross-linked blends are best understood as semi-interpenetrating networks, wherein the PGS- $b$-PTMO forms a continuous network through which Hytrel 3078 chain interpenetrate forming a miscible homogeneous blend.

We conclude that the properties of PGS (prepared from biorenewable and sustainable source of monomers) can be improved by both block copolyester formation with soft segments and blend formation with TPE-E's to yield elastomeric materials with excellent transparency, toughness, and elongation properties (Figure 6). Predominantly aliphatic polyester-polyether elastomers are also biocompatible and offer many opportunities for tailoring physical properties to fulfil the needs of diverse applications. These materials can also be designed with high sustainability quotient because they can be degraded under hydrolytic conditions, unlike cross-linked hydrocarbon-derived elastomers, which persist indefinitely in the environment.

\section{MATERIALS AND METHODS}

Anhydrous glycerol ( $\geq 99 \%)$, SA (99\%), PTMO $\left(M_{\mathrm{n}} \approx 250\right)$, and MDI (98\%) were procured from Sigma-Aldrich and used without further purification. FASCAT 9100 (mono- $n$-butyl tin oxide or butylstannoic acid), which is used as catalyst, was purchased from PMC Organometallix, Beijing, China. The thermoplastic polyester elastomer chosen for this study was Hytrel 3078 and was obtained from DuPont.

Synthesis of Cross-linked PGS (1). An equimolar amount of glycerol and SA was melted and stirred for $2 \mathrm{~h}$ in a $250 \mathrm{~mL}$ two-necked round-bottom flask under nitrogen atmosphere at $135{ }^{\circ} \mathrm{C}$ in the presence of 0.5 wt \% FASCAT 9100 as the catalyst. The reaction pressure was slowly reduced to $400 \mathrm{mbar}$

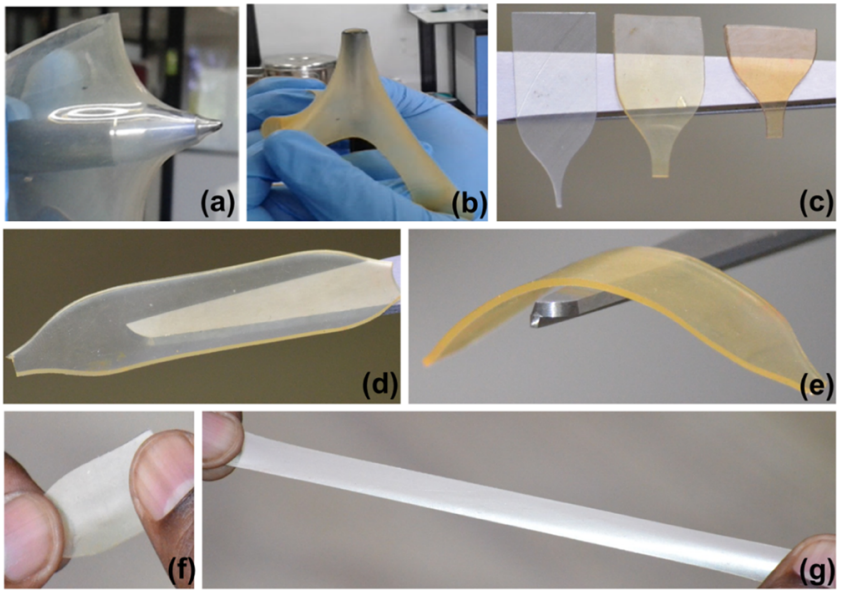

Figure 6. S-IPN thin-film blend samples PGS- $b$-PTMO-H-5 and PGS- $b$-PTMO-H-5-X with a thickness of $\sim 1-1.5 \mathrm{~mm}$ demonstrate the $(a, b)$ strength and toughness of the materials; $(c-e)$ film clarity, transparency, and flexibility; and $(f, g)$ evidence of elongation. Yellow color in the material is due to the presence of the aromatic crosslinker (MDI).

over $4 \mathrm{~h}$ using (SC950 KNF lab) a vacuum pump, and the reaction was allowed to proceed for an additional $4 \mathrm{~h}$ at 135 ${ }^{\circ} \mathrm{C}$. A sample of prepolymer thus obtained was set aside for the spectroscopic analysis. The remaining prepolymer was poured into a Teflon mold and cross-linked in a vacuum oven at 170 ${ }^{\circ} \mathrm{C}$ for $6-7 \mathrm{~h}$. To investigate the effect of cross-linking on mechanical properties of PGS, varying amounts of MDI, that is, $0.5,1,2,3$, and $4 \mathrm{wt} \%$, were added to the PGS prepolymer.

Synthesis of SA-co-PTMO (2). The polyester SA-coPTMO was prepared using SA and PTMO $\left(M_{\mathrm{n}} \approx 250\right)$ in the molar ratio of $1: 0.65 / 0.75 / 0.85$ and 0.5 wt $\%$ of FASCAT 9100 as the catalyst. The reactants were taken in a roundbottom flask and heated in a heating block with a magnetic stirrer. After melting, the flask was evacuated and the pressure was reduced slowly from 1000 to $400 \mathrm{mbar}$ in about $3 \mathrm{~h}$, and the reaction mixture was maintained under this condition for 8 $\mathrm{h}$ at $150{ }^{\circ} \mathrm{C}$ to complete the reaction.

Synthesis of PGS- $b$-PTMO (3). The polyester PGS- $b$ PTMO was prepared by reacting SA-co-PTMO and glycerol $(0.35 / 0.25 / 0.15 \mathrm{~mol})$ for $8 \mathrm{~h}$ at $135{ }^{\circ} \mathrm{C}$. Cross-linking of the polymer was carried out using 2 wt \% (with respect to glycerol) of MDI. The polyester, PGS- $b$-PTMO ( $\sim 10 \mathrm{gm})$, and MDI were dissolved in $50 \mathrm{~mL}$ of chloroform and stirred using a magnetic stirrer for $4-5 \mathrm{~h}$ and then poured in a Teflon mold. The dish was kept in a fume hood for $12 \mathrm{~h}$ to evaporate the solvent. The sample was cross-linked in a vacuum oven at $170{ }^{\circ} \mathrm{C}$ under reduced vacuum $(10 \mathrm{mbar})$ for $8 \mathrm{~h}$.

Preparation of Blends of PGS- $b$-PTMO (3) with TPE and Hytrel 3078 (4). Solution blending of PGS- $b$-PTMO-5 polyester with Hytrel 3078 was carried out in three steps. In step 1 , the polyester was dissolved in chloroform $(1: 2 \mathrm{w} / \mathrm{v})$, and the mixture was stirred for $2 \mathrm{~h}$. In step 2, Hytrel 3078 was dissolved in chloroform $(1: 10 \mathrm{w} / \mathrm{v})$, and the mixture was stirred for $8 \mathrm{~h}$ at $40{ }^{\circ} \mathrm{C}$. In step 3, 10, 20, 30, 40, and $50 \mathrm{wt} \%$ of Hytrel 3078 were added to PGS- $b$-PTMO-5, both as solutions in chloroform and stirred for $10 \mathrm{~h}$. Similar blends were prepared with $2 \mathrm{wt} \% \mathrm{MDI}$ (with respect to the PGS- $b$ PTMO). The solutions were poured into a Teflon dish $(15 \times$ $12 \mathrm{~cm}$ ) and kept in a fume hood for chloroform evaporation. 
Then, these samples were cross-linked at $170{ }^{\circ} \mathrm{C}$ at $10 \mathrm{mbar}$ pressure for $8 \mathrm{~h}$ to obtain elastic thin films.

Characterization. The IR spectra of the samples were recorded on a Perkin Elmer FT-IR spectrophotometer using attenuated total reflection technique. The molecular weight was analyzed using gel permeation chromatography (PL-GPC220, Agilent). THF was used as an eluent at a flow rate of 1.0 $\mathrm{mL} \min ^{-1}$. The temperature of the columns and the refractive index detector was $40{ }^{\circ} \mathrm{C}$. The columns were calibrated using monodisperse polystyrenes $\left(1000-100000 \mathrm{~g} \mathrm{~mol}^{-1}\right)$.

Wide-angle XRD measurements were performed on XEUSS SAXS/WAXS system using a GeniX microsource from Xenocs at $50 \mathrm{kV}$ and $0.6 \mathrm{~mA}$. The $\mathrm{Cu} \mathrm{K} \alpha$ radiation (1.54 $\AA$ ) was collimated with FOX2D mirror and two pairs of scatterless slits from Xenocs. The 2D patterns were documented on a mar345 image plate and processed using Fit $2 \mathrm{D}$ software. All of the measurements were carried out in the transmission mode.

DSC measurements were made on NETZSCH 204F1 Phoenix DSC instrument. Samples of $10-20 \mathrm{mg}$ were used for DSC measurements. PGS samples were first heated to 150 ${ }^{\circ} \mathrm{C}$ from room temperature at a rate of $10{ }^{\circ} \mathrm{C} / \mathrm{min}$. Subsequently, the samples were cooled at a rate of $10{ }^{\circ} \mathrm{C} /$ min to $-50{ }^{\circ} \mathrm{C}$ (whereas SA-co-PTMO and PGS- $b$-PTMO samples were cooled to $-150{ }^{\circ} \mathrm{C}$ ). Hytrel 3078 and the blend samples were first heated to $200{ }^{\circ} \mathrm{C}$ from room temperature at a rate of $10{ }^{\circ} \mathrm{C} / \mathrm{min}$ and cooled to $-100{ }^{\circ} \mathrm{C}$ at a rate of $10{ }^{\circ} \mathrm{C} /$ min. For the polymers, the first cooling and second heating scan were used to determine the melting and crystallization peaks. The peak maximum or minimum was taken as the melting or crystallization temperature, respectively. The peak area was used to calculate the enthalpy.

Mechanical Properties. Stress-strain properties were measured using a Shimadzu AGX-10 universal testing machine at a cross-head speed of $50 \mathrm{~mm} / \mathrm{min}$ and a load cell of $50 \mathrm{kN}$. The uniaxial tensile testing was performed by cutting the thermally cross-linked samples in a rectangular shape with 10 mm gauge length, $5 \mathrm{~mm}$ width, and $\sim 0.75-1.5 \mathrm{~mm}$ thickness.

Sol Content and Swelling Studies. The degree of crosslinking was determined by sol (non-cross-linked network) and gel (cross-linked network) content analysis. The cross-linked samples $(10 \mathrm{~mm}$ diameter and $2 \mathrm{~mm}$ thick) were immersed in chloroform for $24 \mathrm{~h}$ (swollen weight $W_{\mathrm{s}}$ ). The swollen sample was dried in vacuo at $40{ }^{\circ} \mathrm{C}$ for $24 \mathrm{~h}$, and the final weight $\left(W_{\mathrm{d}}\right)$ was recorded. Percent sol content (sol \%) was calculated from $W_{\mathrm{i}}$ and $W_{\mathrm{d}}$, whereas the degree of swelling was obtained as $W_{\mathrm{s}}$ and $W_{\mathrm{d}}$ using the following two equations, respectively

$$
\begin{aligned}
& \operatorname{Sol}(\%)=\frac{W_{\mathrm{i}}-W_{\mathrm{d}}}{W_{\mathrm{i}}} \times 100 \\
& \text { Degree of swelling }(\%)=\frac{\left(W_{\mathrm{s}}-W_{\mathrm{d}}\right)}{W_{\mathrm{d}}} \times 100
\end{aligned}
$$

\section{ASSOCIATED CONTENT}

\section{S Supporting Information}

The Supporting Information is available free of charge on the ACS Publications website at DOI: 10.1021/acsomega.8b02451.

Mechanical and thermal properties of PGS with varying amounts of cross-linker; FT-IR spectra of cross-linked PGS; DSC heating and cooling cycle of cross-linked PGS, PTMO, and poly(SA-PTMO); thermal and mechanical properties of cross-linked and non-crosslinked PGS-b-PTMO-Hytrel 3078; tensile property of Hytrel 3078 elastic thin films; DSC heating and cooling cycle of PGS- $b$-PTMO-1X to $-6 \mathrm{X}$; microstructure of PGS- $b$-PTMO and Hytrel; ${ }^{1} \mathrm{H}$ NMR spectra of Hytrel 3078; and sol content of PGS- $b$-PTMO-H-1 to 4 and PGS- $b$-PTMO-H-1-X to 5-X (PDF)

\section{AUTHOR INFORMATION}

\section{Corresponding Author}

*E-mail: laks@lifecarehll.com, laks77@gmail.com (L.R.). ORCID

Runcy Wilson: 0000-0001-5002-4084

Anuraj Varyambath: 0000-0002-6044-9382

Lakshminarayanan Ragupathy: 0000-0003-2708-2766

Notes

The authors declare no competing financial interest.

\section{ACKNOWLEDGMENTS}

We thank the Bill \& Melinda Gates Foundation's Grand Challenges program for their financial support. We show gratitude to HLL Lifecare Limited, Trivandrum, Kerala, India, for providing all of the facilities and support. S.S. acknowledges the financial support from CSIR in the form of a Bhatnagar Fellowship and the Indian National Science Academy, New Delhi.

\section{REFERENCES}

(1) Drobny, J. G. Handbook of Thermoplastic Elastomers; Elsevier, 2014.

(2) Estes, G. M.; Cooper, S. L.; Tobolsky, A. V. Block polymers and related heterophase elastomers. J. Macromol. Sci., Part C 1970, 4, 313-366.

(3) Spontak, R. J.; Patel, N. P. Thermoplastic elastomers: fundamentals and applications. Curr. Opin. Colloid Interface Sci. 2000, 5, 333-340.

(4) Kane, R. P. New Developments in Copolyester Ether Elastomers. J. Elastomers Plast. 1977, 9, 416-438.

(5) Hillmyer, M. A.; Tolman, W. B. Aliphatic polyester block polymers: renewable, degradable, and sustainable. Acc. Chem. Res. 2014, 47, 2390-2396.

(6) Pepels, M. P. F.; Koeken, R. A. C.; van der Linden, S. J. J.; Heise, A.; Duchateau, R. Mimicking (linear) low-density polyethylenes using modified polymacrolactones. Macromolecules 2015, 48, 4779-4792.

(7) Schneiderman, D. K.; Hillmyer, M. A. 50th anniversary perspective: There is a great future in sustainable polymers. Macromolecules 2017, 50, 3733-3749.

(8) Grego, A. V.; Mingrone, G. Dicarboxylic acids, an alternate fuel substrate in parenteral nutrition: an update. Clin. Nutr. 1995, 14, 143-148.

(9) Wang, Y.; Ameer, G. A.; Sheppard, B. J.; Langer, R. A tough biodegradable elastomer. Nat. Biotechnol. 2002, 20, 602.

(10) Wang, Y.; Kim, Y. M.; Langer, R. In vivo degradation characteristics of poly(glycerol sebacate). J. Biomed. Mater. Res., Part A 2003, 66, 192-197.

(11) Rai, R.; Tallawi, M.; Grigore, A.; Boccaccini, A. R. Synthesis, properties and biomedical applications of poly(glycerol sebacate) (PGS): A review. Prog. Polym. Sci. 2012, 37, 1051-1078.

(12) Harris, J. J.; Lu, S.; Gabriele, P. Commercial challenges in developing biomaterials for medical device development. Polym. Int. 2018, 67, 969-974.

(13) Vilela, C.; Sousa, A. F.; Fonseca, A. C.; Serra, A. C.; Coelho, J. F. J.; Freire, C. S. R.; Silvestre, A. J. D. The quest for sustainable polyesters - insights into the future. Polym. Chem. 2014, 5, 31193141. 
(14) Stempfle, F.; Ortmann, P.; Mecking, S. Long-chain aliphatic polymers to bridge the gap between semicrystalline polyolefins and traditional polycondensates. Chem. Rev. 2016, 116, 4597-4641.

(15) Zhu, Y.; Romain, C.; Williams, C. K. Sustainable polymers from renewable resources. Nature 2016, 540, 354.

(16) Nguyen, V. P. N.; Kuo, N.; Loh, X. J. New biocompatible thermogelling copolymers containing ethylene-butylene segments exhibiting very low gelation concentrations. Soft Matter 2011, 7, 2150-2159.

(17) Zhao, X.; Wu, Y.; Du, Y.; Chen, X.; Lei, B.; Xue, Y.; Ma, P. X. A highly bioactive and biodegradable poly(glycerol sebacate)-silica glass hybrid elastomer with tailored mechanical properties for bone tissue regeneration. J. Mater. Chem. B 2015, 3, 3222-3233.

(18) Komatsu, K.; Chiba, M. The effect of velocity of loading on the biomechanical responses of the periodontal ligament in transverse sections of the rat molar in vitro. Arch. Oral Biol. 1993, 38, 369-375.

(19) Chen, Q.-Z.; Bismarck, A.; Hansen, U.; Junaid, S.; Tran, M. Q.; Harding, S. E.; Ali, N. N.; Boccaccini, A. R. Characterisation of a soft elastomer poly(glycerol sebacate) designed to match the mechanical properties of myocardial tissue. Biomaterials 2008, 29, 47-57.

(20) Kemppainen, J. M.; Hollister, S. J. Tailoring the mechanical properties of 3D-designed poly(glycerol sebacate) scaffolds for cartilage applications. J. Biomed. Mater. Res., Part A 2010, 94, 9-18.

(21) Nijst, C. L. E.; Bruggeman, J. P.; Karp, J. M.; Ferreira, L.; Zumbuehl, A.; Bettinger, C. J.; Langer, R. Synthesis and Characterization of Photocurable Elastomers from Poly(glycerol-co-sebacate). Biomacromolecules 2007, 8, 3067-3073.

(22) Ifkovits, J. L.; Padera, R. F.; Burdick, J. A. Biodegradable and radically polymerized elastomers with enhanced processing capabilities. Biomed. Mater. 2008, 3, 034104.

(23) Chen, Q.-Z.; Liang, S.-L.; Wang, J.; Simon, G. P. Manipulation of mechanical compliance of elastomeric PGS by incorporation of halloysite nanotubes for soft tissue engineering applications. J. Mech. Behav. Biomed. Mater. 2011, 4, 1805-1818.

(24) Patel, A.; Gaharwar, A. K.; Iviglia, G.; Zhang, H.; Mukundan, S.; Mihaila, S. M.; Demarchi, D.; Khademhosseini, A. Highly elastomeric poly(glycerol sebacate)-co-poly(ethylene glycol) amphiphilic block copolymers. Biomaterials 2013, 34, 3970-3983.

(25) Tallawi, M.; Zebrowski, D. C.; Rai, R.; Roether, J. A.; Schubert, D. W.; El Fray, M.; Engel, F. B.; Aifantis, K. E.; Boccaccini, A. R. Poly(Glycerol Sebacate)/Poly(Butylene Succinate-Butylene Dilinoleate) Fibrous Scaffolds for Cardiac Tissue Engineering. Tissue Eng., Part C 2015, 21, 585-596.

(26) Frisch, H. L. Interpenetrating polymer networks. Br. Polym. J. 1985, 17, 149-153.

(27) Dragan, E. S. Design and applications of interpenetrating polymer network hydrogels. A review. Chem. Eng. J. 2014, 243, 572590.

(28) Bajsic, E. G.; Rek, V.; Sendijarevic, A.; Sendijarevic, V.; Frish, K. C. The effect of different molecular weight of soft segments in polyurethanes on photooxidative stability. Polym. Degrad. Stab. 1996, 52, 223.

(29) Antic, V. V.; Govedarica, M. N.; Djonlagic, J. The effect of the mass ratio of hard and soft segments on some properties of thermoplastic poly(ester-siloxane)s. Polym. Int. 2004, 53, 1786-1794.

(30) Zhang, Y.; Feng, Z.; Feng, Q.; Cui, F. The influence of soft segment length on the properties of poly(butylene terephthalate-cosuccinate)-b-poly(ethylene glycol) segmented random copolymers. Eur. Polym. J. 2004, 40, 1297-1308.

(31) Jenkins, M. J.; Cao, Y.; Kukureka, S. N. The effect of molecular weight on the crystallization kinetics and equilibrium melting temperature of poly(tetramethylene ether glycol). Polym. Adv. Technol. 2006, 17, 1-5.

(32) Klempner, D. Interpenetrating polymer networks. Angew. Chem., Int. Ed. Engl. 1978, 17, 97-106.

(33) Klempner, D.; Sperling, L. H.; Utracki, L. A. Interpenetrating Polymer Networks; ACS Publications, 1994.

(34) Shivashankar, M.; Mandal, B. K. A review on interpenetrating polymer network. Int. J. Phram. Phram. Sci 2012, 4, 1-7.
(35) Roland, C. M. Interpenetrating polymer networks (IPN): structure and mechanical behavior. Encyclopedia of Polymeric Nanomaterials, 2015; pp 1004-1011.

(36) Guo, W.; Ashida, M. Mechanical properties of PET short fiberpolyester thermoplastic elastomer composites. J. Appl. Polym. Sci. 1993, 49, 1081-1091.

(37) Hussain, M.; Ko, Y. H.; Choa, Y. H. Significant enhancement of mechanical and thermal properties of thermoplastic polyester elastomer by polymer blending and nanoinclusion. J. Nanomater. 2016, 2016, 1.

(38) Briber, R. M.; Thomas, E. L. Crystallization behaviour of random block copolymers of poly(butylene terephthalate) and poly(tetramethylene ether glycol). Polymer 1985, 26, 8-16.

(39) Xu, J.; Guo, B.-H. Poly(butylene succinate) and its copolymers: Research, development and industrialization. Biotechnol. J. 2010, 5, $1149-1163$.

(40) Schneiderman, D. K.; Hill, E. M.; Martello, M. T.; Hillmyer, M. A. Poly(lactide)-block-poly( $\varepsilon$-caprolactone-co- $\varepsilon$-decalactone $)$-blockpoly(lactide) copolymer elastomers. Polym. Chem. 2015, 6, 36413651.

(41) George, G.; Sisupal, S. B.; Tomy, T.; Pottammal, B. A.; Kumaran, A.; Suvekbala, V.; Gopimohan, R.; Sivaram, S.; Ragupathy, $\mathrm{L}$. Thermally conductive thin films derived from defect free graphenenatural rubber latex nanocomposite: Preparation and properties. Carbon 2017, 119, 527-534. 